\title{
Uso e Influência das Mídias Sociais no Planejamento de Viagens: um estudo quantitativo*
}

Sheila Cristina de Souza

Danielle Fernandes Costa Machadob

\section{Resumo}

A expansão da internet e a ascensão das mídias digitais transformaram a comunicação interpessoal e as relações humanas e comerciais. As mídias sociais são, hoje, ferramentas populares para comunicar, compartilhar e expressar opiniões pessoais e cada vez mais se estabelecem como alternativas aos meios tradicionais no processo de planejamento e decisão de viagens, permitindo uma atualização, quase em tempo real, das informações. 0 objetivo geral do estudo foi medir o uso e a influência das mídias sociais durante o processo de planejamento de viagens turísticas, bem como o nível de confiança atribuído pelos turistas a essas ferramentas on-line, comparativamente a outras fontes de informação disponíveis. A metodologia aplicada foi desenvolvida a partir da adaptação da pesquisa feita anteriormente por Fotis, Buhalis e Rossides, com análises descritivas e críticas dos resultados, e se justifica pela necessidade de ampliar a observação para outros mercados a fim de conhecer as especificidades de cada grupo. A amostragem foi não probabilística, concentrada majoritariamente em residentes da cidade de Belo Horizonte, com participação voluntária on-line. Os achados demonstraram o uso frequente das mídias sociais em todas as fases do planejamento de viagens entre os respondentes, sendo essas ferramentas consideradas as fontes de informação mais confiáveis, atrás apenas dos sites oficiais de turismo e indicações de parentes e amigos.

Palavras-chave: Mídias sociais; Planejamento de viagens; Turismo.

\section{Abstract}

\section{Use and Influence of Social Media on Trip Planning: a quantitative study}

The expansion of the internet and the rise of digital media have transformed interpersonal communication and human and commercial relations. Social media are today popular tools to communicate, share and express personal opinions and they have increasingly become alternatives to traditional media in the process of trip planning and decisions, allowing almost real-time information update. This study aimed to measure the use and influence of social media during the tourism trip planning process and the level of trust that tourists attribute to these online tools, compared with other available sources of information. The applied methodology was developed by adapting a previous study conducted by Fotis, Buhalis, and Rossides, with descriptive and critical analyses of the

* Fomento da Pró-reitoria de Pesquisa da Universidade Federal de Minas Gerais (UFMG). Trabalho vinculado ao projeto de Iniciação Científica Voluntária Destinos turísticos inteligentes e as novas tecnologias de informação e comunicação e apresentado no Fórum Abratur 17, realizado em Recife (PE) de 7 a 9 de junho de 2017. Foi escolhido como um dos melhores trabalhos do evento.

a. Graduada em Turismo pela Universidade Federal de Minas Gerais (UFMG). Belo Horizonte, Minas Gerais, Brasil. E-mail: xecris@gmail.com

b. Professora doutora da Universidade Federal de Minas Gerais (UFMG). Belo Horizonte, Minas Gerais, Brasil. E-mail: daniellefcm@gmail.com 
results, and it is justified by the need to expand the observation to other markets in order to learn about the specificities of each group. This study used nonprobability sampling, mainly focused on residents of the city of Belo Horizonte, with voluntary online participation. The findings demonstrated the frequent use of social media in all stages of trip planning among respondents, with these tools being considered the most reliable sources of information, only behind official tourism websites and recommendations of relatives and friends.

Keywords: Social media; Trip planning; Tourism.

\section{Resumen}

El Uso y la Influencia de los Medios Sociales en la Planificación de Viajes: un estudio cuantitativo

La expansión de internet y el auge de los medios digitales han transformado la comunicación interpersonal y las relaciones humanas y comerciales. Los medios sociales son hoy herramientas populares para comunicar, compartir y expresar opiniones personales, y cada vez más se establecen como alternativa a los medios tradicionales en el proceso de planificación y decisión de viajes, permitiendo una actualización de la información casi en tiempo real. El objetivo general fue medir el uso y la influencia de los medios de comunicación social en el proceso de planificación de viajes, así como el nivel de confianza asignado por los turistas a estas herramientas online en comparación con otras fuentes de información disponibles. La metodología fue desarrollada mediante la adaptación de las investigaciones llevadas a cabo por Fotis, Buhalis y Rossides, con análisis descriptivos y analíticos de los resultados, y se justifica por la necesidad de ampliar la observación a otros mercados con el fin de conocer los detalles de cada grupo. El muestreo es no probabilístico, concentrado en residentes de la ciudad de Belo Horizonte con participación online voluntaria. Los resultados muestran el uso frecuente de los medios sociales en todas las etapas de la planificación de viajes entre los encuestados, con estas herramientas siendo consideradas las fuentes de información más confiables, sólo detrás de los sitios oficiales de turismo y de indicaciones de los familiares y amigos.

Palabras clave: Medios de comunicación social; Planificación de viajes; Turismo.

\section{INTRODUÇÃO}

O objetivo geral deste trabalho é medir o uso e a influência das mídias sociais durante o processo de planejamento de viagens turísticas, bem como o nível de confiança atribuído pelos turistas a essas ferramentas on-line comparativamente a outras fontes de informação disponíveis. Este estudo se justifica pela necessidade de entender a relação entre os usuários brasileiros e as mídias sociais na construção de suas atividades turísticas, uma vez que, segundo estudo similar realizado por Fotis, Buhalis e Rossides (2012), as diferenças culturais influenciam essa interação.

A expansão da internet e a ascensão das mídias digitais transformaram a comunicação interpessoal e as relações humanas e comerciais. 0 turismo, como fenômeno social, cultural e econômico (World Tourism Organization, 2008), é afetado pela mudança de comportamento das pessoas ao se relacionarem e elaborarem desejos e ambições. 0 agir do turista vem sendo profundamente transformado durante o processo de decisão e planejamento de uma viagem, seja na forma como é influenciado, seja na escolha de ferramentas e fontes de 
informação (Xiang \& Gretzel, 2010). No tocante à atividade turística, usuários inspiram-se em viagens de amigos ou conhecidos divulgadas nas redes sociais e descobrem possíveis atividades, serviços ou mesmo equipamentos disponíveis em destinos de interesse. As ferramentas digitais trouxeram maior autonomia para o planejamento e definição de viagens, sendo fundamentais no processo de decisão, ainda que a efetivação da contratação possa acontecer através de empresas ou profissionais do ramo. Parra-López et al. (2011) identificam o uso da internet para buscar informações, para comunicar, ou simplesmente como distração, verificando que o turista direciona seu tempo para pesquisar elementos que enriqueçam sua experiência, bem como para expressar opiniões e compartilhar informações.

Nos últimos anos, um crescente número de pesquisas vem buscando entender as diferentes nuances da dinâmica estabelecida entre os turistas e mídias sociais durante o processo de planejamento de uma viagem. Entre as temáticas pesquisadas, é reconhecida a influência da individualidade dos mercados em função das caraterísticas culturais locais (Gretzel et al., 2008). Fotis, Buhalis e Rossides (2012) contrapõem os resultados de sua pesquisa, realizada com a população da antiga União Soviética, aos indicadores encontrados por Cox et al. (2009) referentes ao uso e à confiabilidade nas mídias sociais entre australianos. No estudo de Cox, os dados demonstraram que os turistas usam as ferramentas on-line predominantemente antes da viagem, após a escolha do destino, e que são fontes de informação menos confiáveis que as tradicionais (sites oficiais do destino ou agências de viagem). Os dados levantados no estudo entre os russos contradizem essa relação, apontando as mídias sociais como fontes mais confiáveis e relacionando seu uso ao pós-viagem, para compartilhar experiências e fotos com amigos e/ou outros turistas.

A ambição deste trabalho é levantar pontos de discussão que fomentem produções científicas voltadas ao contexto nacional do uso de mídias sociais para pesquisa e tomadas de decisão referentes à atividade turística.

\section{REFERENCIAL TEÓRICO}

\section{Mídias sociais}

As mídias sociais são aplicativos da internet construídos sobre as bases ideológicas e tecnológicas da Web $2.0^{1}$ que permitem a criação e troca de Conteúdo Gerado pelo Usuário (CGU) - User-generated content (UGC) ou User-created content (UCC) - de forma participativa e colaborativa, redirecionando a internet para seu objetivo inicial: ser "uma plataforma para facilitar a troca de informações entre os usuários”. (Kaplan \& Haenlein, 2010, p. 60). Apresentam-se como um dos segmentos de mais rápido crescimento na web, com ferramentas que possibilitam aos utilizadores pesquisar, organizar, compartilhar, anotar, opinar e contribuir

1. Web 2.0 é um termo usado pela primeira vez em 2004 para descrever um novo caminho, no qual os desenvolvedores de software e usuários finais passaram a utilizar a World Wide Web, isto é, uma plataforma pela qual conteúdos e aplicativos não são criados e publicados por indivíduos, mas em vez disso, continuamente modificados por todos os usuários de forma participativa e colaborativa (Kaplan \& Haenlein, 2010). 
para o conteúdo em diferentes ambientes (Parra-López, 2011). As mídias sociais são mais que uma nova forma de comunicação, fazem parte, na verdade, de todo ambiente on-line construído a partir da contribuição dos participantes. Segundo Machado (2015), essas ferramentas oferecem aos usuários uma nova plataforma de comunicação semelhante ao boca a boca, que pode gerar o empoderamento dos consumidores. Sua progressão é dinâmica e, apesar de diferentes propostas, não existe uma classificação determinante de seus tipos (Parra-López, 2011; Kaplan \& Haenlein, 2010). A classificação adotada para esta pesquisa segue o estudo de Fotis, Buhalis e Rossides (2012), com a intenção de manter o padrão de observação das mídias sociais: blogs, microblogs (ex.: Twitter), sites de avaliação de viagens (ex.: Booking.com e TripAdvisor), sites de compartilhamento de fotos e vídeos (ex.: YouTube, Flickr), wikis (ex.: Wikipédia e Wikitravel) e redes sociais (ex.: Facebook).

As mídias sociais gozam de um aumento exponencial de sua popularidade entre os internautas e de um incremento dos níveis de utilização e partilha de conteúdo, chegando a ponto de substituir fontes tradicionais de informação (Fotis, Buhalis \& Rossides, 2012). Para Xiang e Gretzel (2010), com o CGU, o consumidor adquiriu maior poder de escolha sobre a informação que acessa e a forma de obtê-la. E se indivíduos recorrem à internet para diversos fins, Parra-López et al. (2011) entendem que também os turistas usam as mídias sociais para expressar opiniões e compartilhar informações.

\section{MÍDIAS SOCIAIS NO TURISMO}

\section{Fases do processo de planejamento da viagem e tipos de uso}

Em estudos sobre o processo de planejamento, Cox et al. (2009) sugerem um modelo adaptado para o consumo de viagens em três etapas (Figura 1): a primeira seria o período de "Pré-viagem", fase de reconhecimento e pesquisa de informações a fim de minimizar os riscos e fomentar a decisão adequada a partir de diferentes fontes; a segunda seria o "Durante", o próprio processo da viagem; e a terceira, "Pós-viagem", fase de avaliação.

Fotis, Buhalis e Rossides (2012) sugerem uma quarta etapa ao dividir a Préviagem em duas fases, (1) antes da escolha do destino e (2) após a escolha do destino, atribuindo diferentes intenções de pesquisa a cada uma:

- Antes da escolha do destino: busca-se informações para ter ideias de aonde ir nas férias ou no feriado, para diminuir opções de destino e para confirmar a escolha do destino.

- Depois da escolha do destino: procuram-se ideias e informações sobre hospedagem e opções de lazer. 
Figura 1 - Modelo do processo de tomada de decisão de consumo de viagens

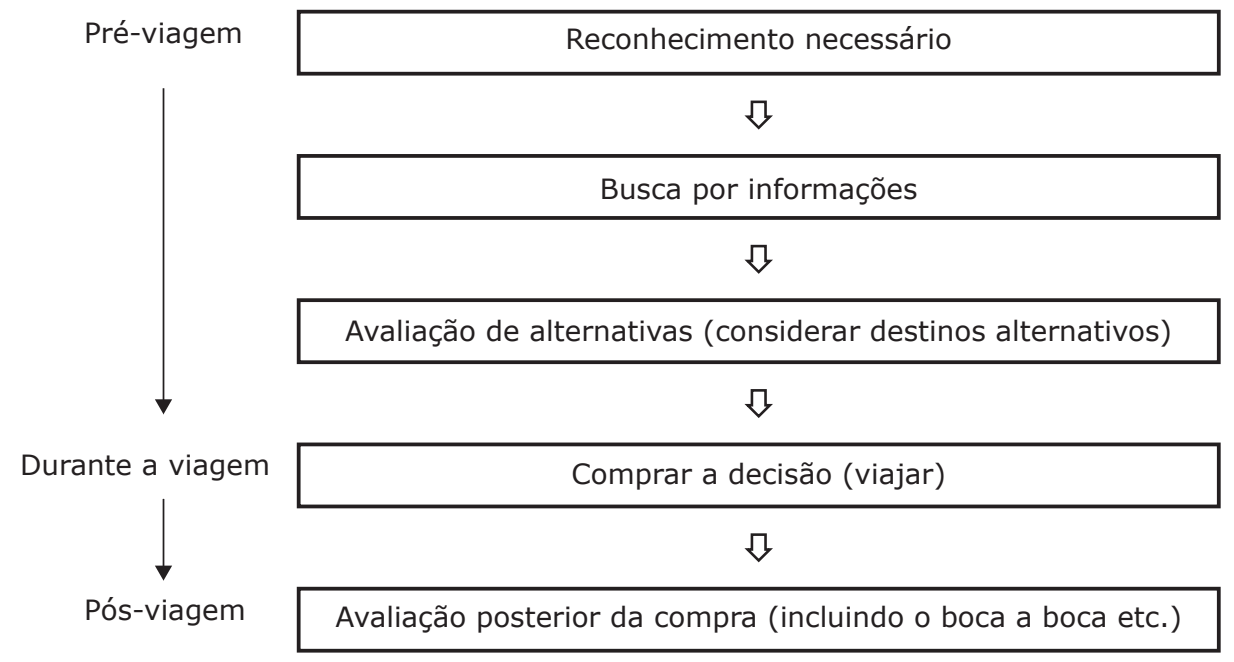

Fonte - Cox et al. (2009, pp. 745), adaptado de Engel, Blackwell e Miniard (1990)

\section{Influência das mídias sociais no planejamento da viagem}

É cada vez maior o uso de comunidades on-line de viagens com o intuito de obter informações para o processo de planejamento e tomada de decisão da compra. Entretanto, não há um consenso sobre como tais comunidades, revisões e opiniões disponíveis nas mídias sociais afetam o comportamento e as escolhas dos turistas (Casaló, Flavián \& Guinalíu, 2011). Parra-López et al. (2011) atribuem o uso de tais aplicativos ao valor percebido pelo consumidor, refletindo na sua fidelização, satisfação e intenção de recomendar e retornar. Para Casaló, Flavián \& Guinalíu (2011), a confiança e a utilidade dos conselhos encontrados on-line são determinantes para a intenção de seguir tais informações. Tal atitude corrobora os achados dos autores já citados, os quais demonstram a preferência dos consumidores por fontes informais nas tomadas de decisão, como comunidades on-line de viagem, revisões de viajantes e indicações em mídias sociais, às fontes formais, como sites oficiais de turismo, agências e campanhas publicitárias.

As mídias sociais são canais de intensa troca de informações onde os usuários são capazes de acessar facilmente grande quantidade de dados relevantes para sua necessidade. Com isso, a confiança a ser estabelecida também é vista como a sensação gerada no viajante durante o processo de tomada de decisão, visto o produto turístico ser intangível antes do consumo e a pesquisa de informações relativas ao destino e/ou às atividades a serem adquiridos reduzir os riscos e aumentar a segurança da escolha (Fotis, Buhalis \& Rossides, 2012; Parra-López et al., 2011). Ao determinar seu destino de viagem, o turista tem diferentes estímulos e informações relacionadas à viagem e ao destino, de maneira consciente ou não. Como consumidor e pelo caráter intangível do produto turístico, ele se vê fortemente motivado a obter informações esclarecedoras para sua escolha (Parra-López et al., 2011). Conteúdos presentes nas mídias sociais agem como fontes geradoras de interesse ao apresentar imagens, dados e experiências (Fotis, Buhalis \& Rossides, 2012). 
Este estudo pretende medir o uso e a influência das mídias sociais durante todas as fases do processo de planejamento da viagem (antes, durante e depois), bem como o nível de confiança atribuído pelos turistas a essas ferramentas on-line comparativamente a outras fontes de informação disponíveis. Ao reproduzir o estudo realizado por Fotis, Buhalis \& Rossides (2012), busca-se ainda verificar duas hipóteses levantadas pelos autores:

H1: As mídias sociais são predominantemente utilizadas antes da viagem para buscar informações.

H2: Informações sobre viagens em mídia social são mais confiáveis do que publicidade em meios de comunicação, agências de viagens e sites oficiais de turismo.

\section{METODOLOGIA}

O questionário aplicado para este estudo foi construído a partir de tradução livre do inglês e adaptação do instrumento produzido e utilizado por Fotis, Buhalis e Rossides (2012). As questões para determinação do perfil sociodemográfico foram baseadas na publicação da Secretaria de Comunicação Social da Presidência da República, Pesquisa brasileira de mídia 2015: hábitos de consumo de mídia pela população brasileira (Brasil, 2014). Para as questões subjetivas optou-se pela manutenção da escala Likert de sete pontos, adotada no estudo original.

Além dos dados sociodemográficos, o questionário foi organizado em dois construtos, de acordo com pesquisas anteriores sobre o tema e com os objetivos do estudo:

1)Uso da internet e das mídias sociais - fundamentado na Pesquisa brasileira de mídia (Brasil, 2014);

2)Uso das mídias sociais no planejamento da viagem - para determinar a) período de pesquisa nas mídias sociais e tipo de uso feito pelo turista; b) percepção da influência das ferramentas on-line nas escolhas da viagem; c) mudanças nos planos de viagem por influência do CGU; d) confiança nas diferentes fontes de informação das mídias sociais no planejamento da viagem.

0 questionário foi construído na plataforma do Google Forms e disponibilizado on-line entre os dias 27 de outubro e 6 de novembro, com divulgação através da rede de amigos nas mídias sociais identificadas como de maior uso pelos brasileiros: Facebook, Instagram, Google+, Twitter e WhatsApp (Brasil, 2014), além de e-mail.

Foram coletados 657 questionários, sendo reconhecidos doze repetidos, totalizando uma amostra de 635 pessoas. Nos questionários válidos, pode-se observar cinco grupos de respondentes, de acordo com as respostas às quatro perguntas-chave (Tabela 1). 
Tabela 1 - Grupos da amostra

\begin{tabular}{|l|l|c|}
\hline Grupo & Pergunta-chave & $\begin{array}{c}\text { Número de } \\
\text { respondentes }\end{array}$ \\
\hline $\begin{array}{c}\text { Grupo 1: Não usa internet } \\
\text { Grupo 2: Não usa mídias sociais }\end{array}$ & $\begin{array}{l}\text { Com que frequência você utiliza a internet? } \\
\text { Com que frequência você utiliza mídias sociais? }\end{array}$ & 11 \\
\hline $\begin{array}{c}\text { Grupo 3: Não viajou nos } \\
\text { últimos 12 meses }\end{array}$ & $\begin{array}{l}\text { Você realizou alguma viagem a LAZER nos } \\
\text { últimos 12 meses? }\end{array}$ & 128 \\
\hline $\begin{array}{c}\text { Grupo 4: Não usou mídias } \\
\text { sociais no processo } \\
\text { de planejamento } \\
\text { da viagem }\end{array}$ & $\begin{array}{l}\text { Tomando como base a sua ÚLTIMA viagem } \\
\text { a lazer, você fez uso de alguma mídia social } \\
\text { para planejar e compartilhar informações, }\end{array}$ & \\
\hline antes, durante e depois da viagem? & 78 \\
\hline Grupo 5: Foco do estudo & & 417 \\
\hline
\end{tabular}

Fonte - Dados da pesquisa

Os resultados obtidos foram ponderados através do programa SPSS Statistics 22.0 para observação descritiva da amostra, seguida de uma análise estatística com cruzamento de dados, a fim de responder a problemática deste estudo: qual a influência das mídias sociais no processo de construção das viagens de seus usuários e como eles percebem a confiabilidade das informações disponíveis? Tais cruzamentos foram realizados através do Teste Qui-quadrado $\left(\mathrm{x}^{2}\right)$, que permite constatar possíveis associações de variáveis independentes. Com o intuito de verificar a componente cultural diferente entre esta pesquisa e a original, já mencionada, identificando possíveis discrepâncias de achados, utilizou-se o Teste t, que verifica se as médias de uma mesma variável em duas amostras independentes são significativamente diferentes.

As categorias utilizadas para a descrição dos resultados foram determinadas a partir da observação das frequências de respostas para um agrupamento adaptado aos dados da pesquisa e que melhor permitisse o entendimento da amostra. Contudo, para as análises estatísticas foram necessárias algumas adaptações da categorização. Seguindo as condições do Teste Qui-quadrado quanto ao número de categorias, idealmente reduzidas nos cruzamentos e com não menos que dez indivíduos cada uma, realizou-se a recodificação das variáveis sociodemográficas (idade, escolaridade e renda). Para o Teste t foi necessária nova recodificação das variáveis idade e escolaridade, no interesse de comparar os achados dos dois estudos. Nos reagrupamentos das categorias de escolaridade, foram descartados os entrevistados com ensino fundamental (cinco indivíduos), uma vez que não se enquadravam às demais categorias e eram pouco representativos dentro da amostra.

\section{RESULTADOS}

\section{Perfil da amostra}

A idade média dos entrevistados é de 34,3 anos, com predominância das faixas etárias entre 18 e $25(33,1 \%)$ e entre 26 e 35 anos $(28,2 \%)$. A distribuição restante deu-se com $17,5 \%$ dos respondentes entre 36 a 45 anos, $13,1 \%$ com 46 a 55 e $8,2 \%$ acima de 55 anos. Observa-se, portanto, uma amostra com ampla distribuição de idades dos respondentes. Os entrevistados são, em sua maioria, do sexo 
feminino (58\%), e o restante, do sexo masculino (43,3\%). A predominância de mulheres era esperada, devido ao observado por Fotis, Buhalis e Rossides (2012) quanto à maior predisposição delas a participar de entrevistas voluntariamente e, possivelmente, por seu papel nas decisões sobre viagens. A amostra apresentou o ensino superior incompleto como nível de escolaridade predominante $(30,7 \%)$, seguido de ensino superior completo $(27,7 \%)$, o que pode ser explicado pela distribuição do questionário através da rede de contatos da pesquisadora, fato que influenciou o perfil escolar dos participantes da pesquisa. Outros níveis de escolaridade encontrados foram: ensino fundamental incompleto $(0,3 \%)$; ensino fundamental completo $(0,5 \%)$; ensino médio incompleto $(2,0 \%)$; ensino médio completo $(7,4 \%)$; curso técnico $(3,0 \%)$; especialização $(16,4 \%)$; MBA $(1,4 \%)$; mestrado $(7,2 \%)$; doutorado $(2,7 \%)$; e pós-doutorado $(0,6 \%)$.

Os entrevistados são brasileiros, predominantemente residentes no Brasil, estando a maior parte deles em Minas Gerais (91,7\%). Belo Horizonte, cidade de residência da pesquisadora, responde por $72,4 \%$ dos participantes. A renda mensal familiar média (Gráfico 1) entre os 551 entrevistados que responderam essa questão é de $\mathrm{R} \$ 7.120,68$, influenciada por valores atípicos altos, acima de $\mathrm{R} \$ 30.000,00$. A mediana da renda demonstra essa alteração, ao apresentar o valor de $\mathrm{R} \$ 5.500,00$. De modo a facilitar o estudo dos dados obtidos, optou-se por agrupar as respostas em valores a partir do salário mínimo atual, $\mathrm{R} \$ 880,00$.

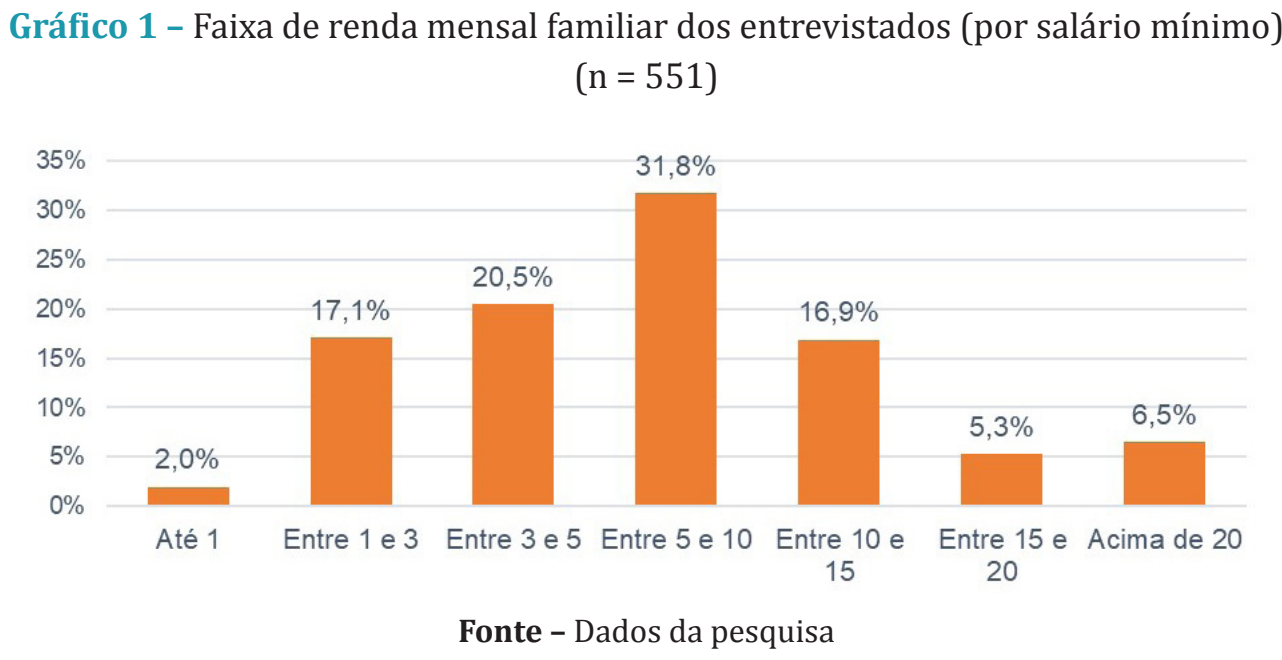

A representação foi próxima ao estudo base $(n=346)$, que foi realizado com residentes de países da antiga União Soviética, principalmente a Rússia, e se caracterizou por maioria de mulheres entre 25 e 39 anos graduadas (o estudo não informou se graduação completa ou incompleta). Isso permite fazer possíveis inferências sobre o componente cultural nos diferentes comportamentos dos turistas quanto ao uso das mídias sociais durante o planejamento de suas viagens.

\section{Uso da internet e das mídias sociais}

Entre os 635 entrevistados, apenas 1 (0,2\%) afirmou não utilizar a internet, enquanto quase $97 \%$ disseram acessar a rede diariamente $(91 \%$ mais de uma vez por dia e $5,8 \%$ sete vezes por semana); 2,6\% afirmaram usá-la algumas vezes 
por semana e 0,5\%, menos de uma vez por semana. Apesar dos números mais distribuídos entre as opções, o uso de mídias sociais apresentou um comportamento semelhante: quase $90 \%$ relataram o uso diário: 78,6\% mais de uma vez por dia e 8,2\% sete vezes por semana (Tabela 2). Apenas $11(1,7 \%)$ dos 634 entrevistados que responderam essa questão afirmaram não utilizar mídias sociais.

Tabela 2 - Uso de mídias sociais no dia a dia

\begin{tabular}{|l|c|c|}
\hline & Frequência & Porcentagem \\
\hline Nunca & 11 & $1,7 \%$ \\
\hline Menos de uma vez por semana & 7 & $1,1 \%$ \\
\hline 1x por semana & 7 & $1,1 \%$ \\
\hline 2x por semana & 3 & $0,5 \%$ \\
\hline 3x por semana & 16 & $2,5 \%$ \\
\hline 4x por semana & 11 & $1,7 \%$ \\
\hline 5x por semana & 16 & $2,5 \%$ \\
\hline 6x por semana & 12 & $1,9 \%$ \\
\hline $7 x$ por semana & 52 & $8,2 \%$ \\
\hline Mais de uma vez por dia & 499 & $78,7 \%$ \\
\hline Total & 634 & $100 \%$ \\
\hline
\end{tabular}

Os aplicativos de mensagem instantânea e o Facebook foram apontados como as mídias sociais mais utilizadas pelos respondentes (Gráfico 2), assinalados por $88,1 \%$, seguidos pelo YouTube (82\%). Entre as ferramentas direcionadas à atividade turística, as mais citadas foram Decolar.com (31,9\%), Booking.com $(25,2 \%)$ e TripAdvisor $(24,6 \%)$. Ressalta-se que essa pergunta permitia mais de uma resposta.

Gráfico 2 - Mídias sociais utilizadas pelos entrevistados (n = 634)

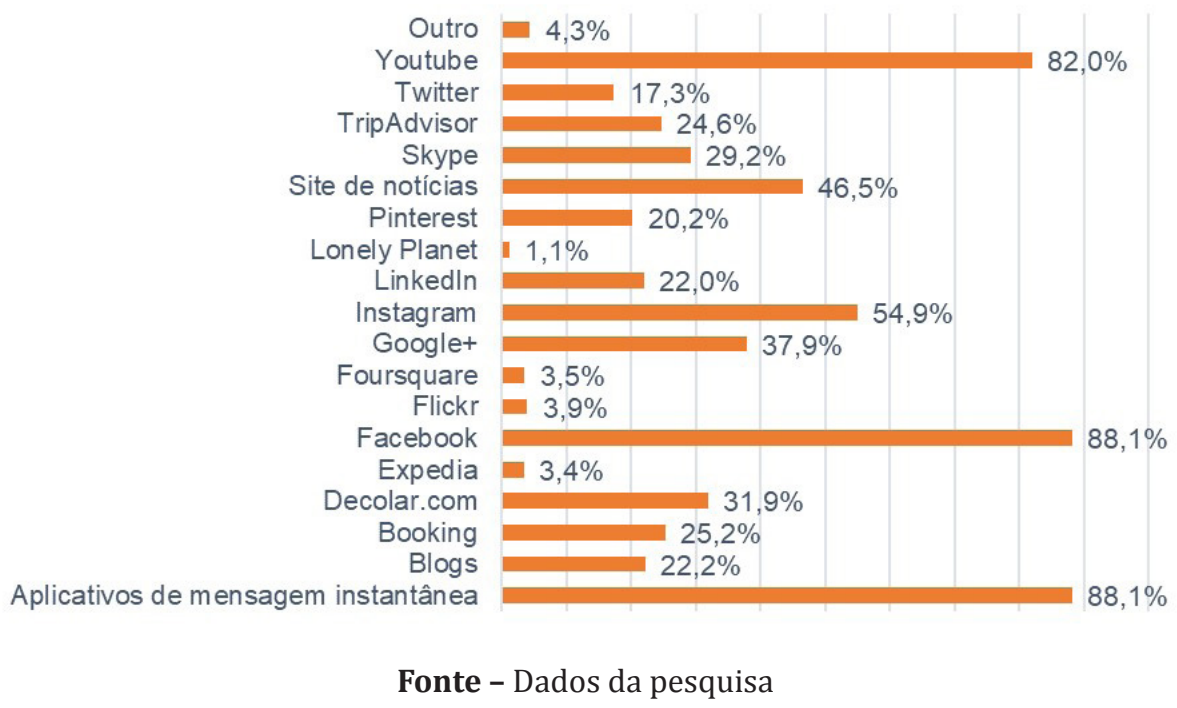

0 uso da internet e das mídias sociais na amostra revelaram um hábito intenso: $97 \%$ dos respondentes se conectam à rede mundial diariamente e 78,7\% usam 
alguma mídia social mais de uma vez por dia. A porcentagem elevada de acesso à internet é consideravelmente maior que a encontrada no estudo de amostragem nacional (Brasil, 2014) - 37\% - e se explica pelas diferentes abordagens utilizadas, uma vez que na pesquisa encomendada pela Secretaria de Comunicação Social da Presidência da República a entrevista foi realizada em domicílios de todos os estados do Brasil, com uma amostragem representativa de toda a população brasileira. Apesar de não haver dados nesse estudo sobre a intensidade de utilização específica das mídias sociais entre brasileiros, foi possível observar o uso também elevado na pesquisa de Fotis, Buhalis e Rossides (2012), em que quase 50\% dos entrevistados afirmaram acessar alguma mídia social várias vezes por dia. Importa compreender que tais autores optaram por distribuir o questionário on-line, como nesta pesquisa.

Entre as mídias sociais mais utilizadas pelos entrevistados, o comportamento da amostra repetiu o padrão nacional, registrando maior uso do Facebook e de aplicativos de mensagem instantânea, ainda que na PBM (Brasil, 2014) essas ferramentas não tenham apresentado valores igualmente elevados (83\% para Facebook e 58\% para aplicativos de mensagem instantânea). A PBM não contemplou ferramentas direcionadas ao tema viagem. Contudo, quanto ao uso de mídias gerais os relatos apresentaram perfil semelhante, não em valores, como já discutido a respeito das diferentes abordagens das pesquisas, mas na eleição das ferramentas mais utilizadas (Tabela 3).

Tabela 3 - Comparativo das mídias sociais mais utilizadas

\begin{tabular}{|l|c|c|}
\hline & Brasil (2014) & Pesquisa atual \\
\hline Facebook & $\mathbf{n = 1 8 3 0 0}$ & $\mathbf{n}=\mathbf{6 3 4}$ \\
\hline Aplicativos & (WhatsApp) 58,0\% & $88,1 \%$ \\
\hline YouTube & $17,0 \%$ & $88,1 \%$ \\
\hline Instagram & $12,0 \%$ & $82,0 \%$ \\
\hline Google + & $8,0 \%$ & $54,9 \%$ \\
\hline Twitter & $5,0 \%$ & $37,9 \%$ \\
\hline Skype & $4,0 \%$ & $17,3 \%$ \\
\hline LinkedIn & $1,0 \%$ & $29,2 \%$ \\
\hline Outros & Fonte - Brasil (2014 e dados da pesquisa \\
\hline
\end{tabular}

\section{Uso das mídias sociais no planejamento da viagem}

0 grupo 3 (cf. Tabela 1) foi determinado após a terceira pergunta-chave (Você realizou alguma viagem a LAZER nos últimos 12 meses?). Responderam negativamente 128 participantes (20,5\%), os quais tiveram o questionário interrompido. Entre os 495 (grupo 4) que realizaram pelo menos uma viagem, 81,6\% escolheram um destino nacional, e 84,2\% (417 respondentes, grupo 5) utilizaram alguma mídia social no planejamento e/ou compartilhamento de informações da viagem.

Confirmando o elevado uso de mídias sociais no processo de planejamento turístico, observa-se alta influência dessas ferramentas on-line nas escolhas relacionadas 
à viagem quando quase $70 \%$ dos entrevistados atribuíram a elas valores a partir de 5, numa escala de 1 a 7 pontos, acima do valor médio (Tabela 4). Além disso, 48,4\% dos respondentes afirmaram ter alterado seus planos originais de viagem a partir do conteúdo on-line, embora a maior parte $(36,7 \%)$ tenha realizado apenas alterações menores (Tabela 5). 30,9\% afirmaram não ter feito qualquer mudança com base nas informações presentes nas mídias sociais, o que levanta a hipótese da busca de elementos apenas complementares às decisões já tomadas a respeito da viagem.

Tabela 4 - Influência das mídias sociais na viagem

\begin{tabular}{|c|c|c|c|}
\hline & Frequência & Porcentagem \\
\hline & 1 & 9 & $2,2 \%$ \\
\hline & 2 & 13 & $3,1 \%$ \\
\hline & 3 & 26 & $6,2 \%$ \\
\hline & 5 & 78 & $18,7 \%$ \\
\hline & 6 & 142 & $34,1 \%$ \\
\hline Total & 7 & 82 & $19,7 \%$ \\
\hline Média & & 67 & $16,1 \%$ \\
\hline
\end{tabular}

$\mathrm{n}=417$, escala Likert de 7 pontos: $1=$ nenhuma, $7=$ completamente Fonte - Dados da pesquisa

Os entrevistados que utilizaram as mídias sociais no planejamento de suas viagens nos últimos doze meses $(n=417)$ indicaram nota média de 5,03 (na escala Likert) para a influência de tais ferramentas nas escolhas da viagem, enquanto no estudo de Fotis, Buhalis e Rossides (2012), na mesma escala, a média encontrada foi de 4,84. Tal diferença é estatisticamente significativa (Teste t $p=0,006$; intervalo de confiança de 95\%), demonstrando que os brasileiros pesquisados atribuem maior influência a esses recursos tecnológicos sobre suas escolhas turísticas. Analisando o uso das mídias sociais no planejamento da viagem, não foram observadas relações estatisticamente relevantes, para nível de confiança de 95\%, entre a renda, a escolaridade e o sexo dos entrevistados. A variável idade recodificada (entre 18 e 25; 26 e 35; 36 e 45 e acima de 46 anos) mostrou diferença significativa entre os grupos, $\mathrm{x}^{2}$ $(\mathrm{p}=0,006)$, indicando maior uso das ferramentas por entrevistados de 26 a 35 anos.

Tabela 5 - Alterações dos planos de viagem por influência de conteúdo das mídias sociais

\begin{tabular}{|l|c|c|}
\hline & Frequência & Porcentagem \\
\hline Não tenho certeza, não lembro & 86 & $20,6 \%$ \\
\hline Não fiz nenhuma mudança nos planos originais & 129 & $30,9 \%$ \\
\hline Fiz algumas mudanças nos meus planos originais & 153 & $36,7 \%$ \\
\hline Fiz mudanças significativas nos meus planos originais & 46 & $11,0 \%$ \\
\hline Mudei totalmente os meus planos originais & 3 & $0,7 \%$ \\
\hline Total & 417 & $100 \%$ \\
\hline
\end{tabular}

Fonte - Dados da pesquisa 
A influência das mídias sociais foi medida através de cinco afirmativas, com intuito de observar mais claramente como as informações obtidas on-line alteraram as escolhas dos turistas. 0 estudo original apresentava apenas quatro afirmativas, às quais optou-se por acrescentar uma nova, na intenção de abranger possíveis grupos específicos. Novamente o comportamento da amostra obtida foi similar ao encontrado na pesquisa em que esta se baseou (Tabela 6). Ambos os estudos demonstram que a maioria dos entrevistados reconhece ter feito mudanças nos planos originais a partir do que pesquisou, ainda que os brasileiros tenham tido grande número de respostas incertas.

Tabela 6 - Comparativo das alterações dos planos de viagem por influência de conteúdo das mídias sociais

\begin{tabular}{|l|c|c|}
\hline & $\begin{array}{c}\text { Fotis, Buhalis e Rossides } \\
\text { (2012) }\end{array}$ & Pesquisa atual \\
\cline { 2 - 3 } & $\mathbf{n = 2 7 3}$ & $\mathbf{n = 4 1 7}$ \\
\hline Não tenho certeza, não lembro & $2,2 \%$ & $20,6 \%$ \\
\hline $\begin{array}{l}\text { Não fiz nenhuma mudança nos } \\
\text { planos originais }\end{array}$ & $33,7 \%$ & $30,9 \%$ \\
\hline $\begin{array}{l}\text { Fiz algumas mudanças nos meus } \\
\text { planos originais }\end{array}$ & $49,5 \%$ & $36,7 \%$ \\
\hline $\begin{array}{l}\text { Fiz mudanças significativas nos } \\
\text { meus planos originais }\end{array}$ & $14,7 \%$ & $11,0 \%$ \\
\hline $\begin{array}{l}\text { Mudei totalmente os meus } \\
\text { planos originais }\end{array}$ & - & $0,7 \%$ \\
\hline
\end{tabular}

Fonte - Adaptado de Fotis, Buhalis e Rossides (2012)

Dessa forma, em ambos os estudos, apesar de não atribuírem notas altas à influência das mídias sociais durante o planejamento da viagem - média entre 4 e 5 na escala de 7 pontos -, a maior parte dos entrevistados afirma ter alterado algum aspecto de sua viagem a partir de conteúdos encontrados nas mídias sociais. Ainda assim, cerca de um terço dos participantes dos estudos parece utilizar as informações disponíveis on-line apenas para complementar seu planejamento, sem alterar os planos originais.

\section{As mídias sociais nas diferentes fases da viagem}

A fim de reconhecer e entender melhor a motivação do uso das mídias sociais durante o processo de viagem, o estudo de Fotis, Buhalis e Rossides (2012) elencou doze afirmativas, distribuídas entre as quatro fases de uma viagem entendidas por eles: antes da viagem e antes da escolha do destino; antes da viagem e após a escolha do destino; durante a viagem; após a viagem). Para esta pesquisa, optou-se por acrescentar afirmativas às propostas no estudo base, no intuito de identificar melhor as nuances das etapas e do comportamento do turista participante (cf. Tabela 6). Para fins comparativos, demonstram-se apenas as afirmativas presentes nos dois estudos (Gráfico 3). 
Para os respondentes deste estudo, as motivações mais recorrentes foram a busca de informações antes da viagem, principalmente "Procurando ideias e informações sobre atrações e atividades de lazer" (81,5\%), e o compartilhamento da experiência depois da viagem com "Para compartilhar minhas experiências e fotos com meus amigos e/ou outros turistas" (81,3\%). Antes de escolher para onde viajar, a pesquisa é centrada na busca de ideias de destino $(66,7 \%)$ e na confirmação dele $(68,6 \%)$. Antes da viagem, a pesquisa por hospedagem é feita pela maioria dos entrevistados (77\%), o que não se repete com as opções de alimentação $(44,8 \%)$. Durante a viagem, os motivos para uso de mídias sociais mais referidos foram a busca de informações sobre atrações disponíveis no local $(67,6 \%)$ e específicas (60\%), ou seja, de interesse particular do turista, além do uso para manter contato com amigos (60,9\%). Descrição de comentários e análises sobre a viagem em mídias específicas obtiveram menores valores de resposta $(24,9 \%)$ (Tabela 7$)$.

Tabela 7 - Formas de uso de mídias sociais na viagem $(\mathrm{n}=417)$

\begin{tabular}{|c|c|}
\hline \multicolumn{2}{|l|}{ Antes da viagem - antes da escolha do destino } \\
\hline No início da pesquisa para ter ideias de aonde ir nas férias/feriado & $66,7 \%$ \\
\hline Para diminuir minhas opções de destino & $14,4 \%$ \\
\hline Para confirmar minha escolha do destino & $68,6 \%$ \\
\hline \multicolumn{2}{|l|}{ Antes da viagem - depois da escolha do destino } \\
\hline Procurando ideias e informações sobre opções de hospedagem & $77,0 \%$ \\
\hline $\begin{array}{l}\text { Procurando ideias e informações sobre atrações e atividades } \\
\text { de lazer }\end{array}$ & $81,5 \%$ \\
\hline Procurando ideias e informações sobre opções de alimentação & $44,8 \%$ \\
\hline \multicolumn{2}{|l|}{ Durante a viagem } \\
\hline $\begin{array}{l}\text { Procurando ideias e informações sobre atrações e atividades } \\
\text { de lazer }\end{array}$ & $67,6 \%$ \\
\hline Procurando ideias e informações sobre opções de alimentação & $48,7 \%$ \\
\hline $\begin{array}{l}\text { Para encontrar informações sobre atrações e atividades de lazer } \\
\text { específicas }\end{array}$ & $60,0 \%$ \\
\hline $\begin{array}{l}\text { Para fazer comentários e análises sobre minha experiência } \\
\text { no destino }\end{array}$ & $24,9 \%$ \\
\hline Para manter contato com amigos & $60,9 \%$ \\
\hline $\begin{array}{l}\text { Visitei mídias sociais que não tinham relação com informações } \\
\text { sobre minha viagem }\end{array}$ & $41,7 \%$ \\
\hline \multicolumn{2}{|l|}{ Depois da viagem } \\
\hline $\begin{array}{l}\text { Para compartilhar minhas experiências e fotos com meus amigos } \\
\text { e/ou outros turistas }\end{array}$ & $81,3 \%$ \\
\hline $\begin{array}{l}\text { Para avaliar e comentar sobre meu destino de viagem e meu local } \\
\text { de hospedagem }\end{array}$ & $38,8 \%$ \\
\hline $\begin{array}{l}\text { Sou um visitante regular de mídias sociais relacionadas com } \\
\text { turismo para ter ideias e inspirações para minhas próximas viagens }\end{array}$ & $31,9 \%$ \\
\hline
\end{tabular}

Fonte - Dados da pesquisa 
Gráfico 3 - Comparativo do uso das mídias sociais antes da viagem, depois da escolha do destino

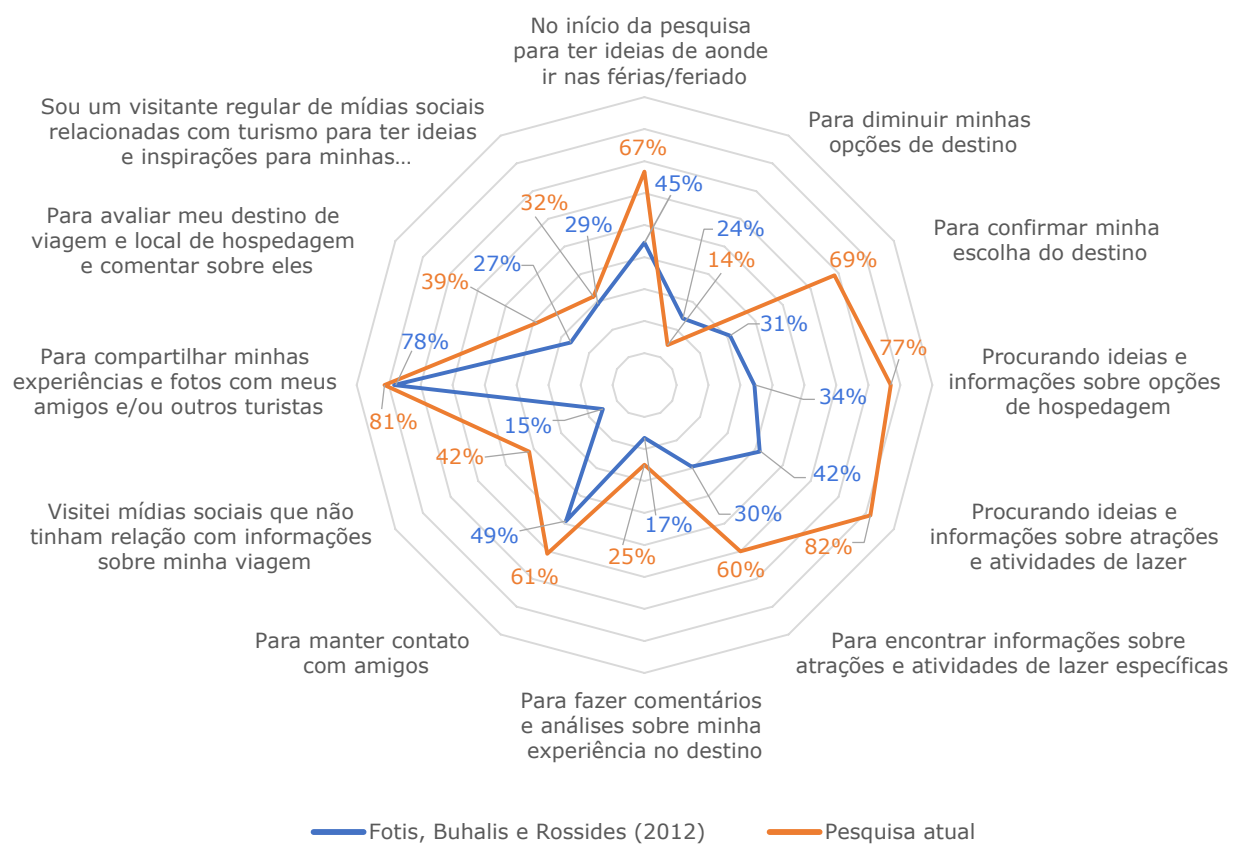

Fonte - Adaptado de Fotis, Buhalis e Rossides (2012)

0 comportamento das duas amostras assemelha-se na distribuição das referências de uso das mídias sociais em diferentes fases da viagem. Ainda que os valores nem sempre sejam próximos, os entrevistados de ambas as pesquisas têm mais propensão para os mesmos usos. A única motivação que não demonstrou tal semelhança foi a intenção de diminuir opções de destino antes da viagem e antes da escolha do destino, quando os dados da pesquisa anterior acumularam maior porcentagem de resposta que nesta. Em todas as outras variáveis, em diferentes proporções, obteve-se maior percentual de uso dos brasileiros.

Ao se observarem as variáveis e as fases da viagem, os achados de Fotis, Buhalis e Rossides demonstraram que o uso principal das mídias sociais relacionado à viagem acontece predominantemente depois dela, para compartilhamento da experiência, segundo 78\% dos entrevistados. Embora Parra-López et al. (2011) corroborem esse achado em seu estudo, e apesar de tal motivação ter obtido valor alto na pesquisa atual $(81,3 \%)$, não foi a maior das variáveis, já que a mais citada se refere ao período antes da viagem, na busca por informações de lazer $(81,5 \%)$. Novamente para tais diferenças cabe citar Parra-López et al. (2011), que demonstram a falta de consenso sobre a força motivadora do uso das mídias sociais no processo de planejamento de viagens e sobre seu poder de influência nas decisões. As nuances culturais podem ser entendidas como potenciais causadores dessas variações, como sugerido no estudo original.

\section{A confiança nas mídias sociais}

Para os entrevistados, a confiança nas informações presentes nas mídias sociais está, em média, ainda dentro da faixa de indiferença $(4,78)$. Recordando que a escala Likert utilizada no questionário foi de 7 pontos, a pontuação de 1 a 3 corresponde 
ao indicativo de diferentes graus de não confiança; entre 5 e 7 estão os graus de confiança. Dessa forma, o meio da escala, nota 4, caracteriza-se como ponto de indiferença, quando o entrevistado não considera as informações encontradas online como totalmente confiáveis ou desacreditadas. As fontes com maiores médias encontradas foram "Amigos e parentes" (5,63) e "Sites oficiais de turismo" $(5,18)$, ainda que também tenham obtido valores muito próximos do meio da escala. (Tabela 8).

Tabela 8 - Média de confiança nas diferentes fontes de informações sobre viagem

\begin{tabular}{|l|c|c|}
\hline & Média & \multicolumn{1}{|c|}{ SD } \\
\hline Amigos e parentes & 5,63 & $(1,41)$ \\
\hline Informações fornecidas por outros turistas na Internet & 4,78 & $(1,17)$ \\
\hline Informações em mídias sociais & 4,78 & $(1,22)$ \\
\hline Sites oficiais de turismo & 5,18 & $(1,16)$ \\
\hline Programas e documentários de TV, rádio ou artigos de jornais e revistas & 4,84 & $(1,20)$ \\
\hline Agências de viagem & 4,65 & $(1,35)$ \\
\hline Propagandas de TV, rádio, jornal e revista & 4,35 & $(1,26)$ \\
\hline
\end{tabular}

$\mathrm{n}=417$, Escala Likert de 7 pontos: 1 = Não confio de forma alguma, 7 = Confio totalmente

Fonte - Dados da pesquisa

A percepção da confiança da amostra estudada nesta pesquisa demonstrou um público mais conservador, que atribui maior crédito a fontes tradicionais. Fontes relacionadas à comercialização de produtos de viagens (agências; propagandas de TV, rádio, jornal e revista) foram apontadas com desconfiança e receberam os valores mais baixos na já citada escala Likert. As mídias sociais caracterizaram-se por confiança intermediária.

Comparativamente ao estudo de Fotis, Buhalis e Rossides (2012), o grau de confiança é significativamente diferente para todas as fontes apresentadas no questionário (Tabela 9). Apesar de apontarem Amigos e parentes e Outros turistas na internet como fontes confiáveis, os brasileiros da amostra revelaram-se menos seguros quanto às mídias sociais que os residentes nos países da antiga União Soviética. Em contrapartida, consideraram melhor as demais fontes. Dessa forma, este estudo contradiz os achados da pesquisa original, que encontrou maior confiança nas mídias sociais em relação às agências de viagem e sites oficiais de turismo.

Tabela 9 - Teste t quanto à confiança em potenciais fontes de informação sobre viagens

\begin{tabular}{|l|l|l|l|l|l|l|}
\hline & \multicolumn{1}{|c|}{$\mathbf{t}$} & $\mathbf{d f}$ & $\begin{array}{c}\text { Sig. } \\
\text { 2 extremidades }\end{array}$ & $\begin{array}{c}\text { Diferença } \\
\text { média }\end{array}$ & $\begin{array}{c}\mathbf{9 5 \%} \text { Intervalo de } \\
\text { Confiança da Diferença }\end{array}$ \\
\hline & & & & & \\
Inferior & Superior \\
\hline Amigos e parentes & $-12,778$ & 416 & 0,000 & $-0,729$ & $-0,84$ & $-0,62$ \\
\hline $\begin{array}{l}\text { Outros turistas } \\
\text { na internet }\end{array}$ & $-6,258$ & 416 & 0,000 & $-0,373$ & $-0,49$ & $-0,26$ \\
\hline Mídias sociais & 2,019 & 416 & 0,044 & 0,114 & 0,00 & 0,23 \\
\hline $\begin{array}{l}\text { Sites oficiais } \\
\text { de turismo }\end{array}$ & 13,244 & 416 & 0,000 & 0,817 & 0,70 & 0,94 \\
\hline
\end{tabular}


Tabela 9 - Continuação

\begin{tabular}{|c|c|c|c|c|c|c|}
\hline & \multirow[t]{2}{*}{$\mathbf{t}$} & \multirow[t]{2}{*}{ df } & \multirow{2}{*}{$\begin{array}{c}\text { Sig. } \\
2 \text { extremidades }\end{array}$} & \multirow{2}{*}{$\begin{array}{l}\text { Diferença } \\
\text { média }\end{array}$} & \multicolumn{2}{|c|}{$\begin{array}{c}\text { 95\% Intervalo de } \\
\text { Confiança da Diferença }\end{array}$} \\
\hline & & & & & Inferior & Superior \\
\hline $\begin{array}{l}\text { Programas e } \\
\text { documentários }\end{array}$ & 14,927 & 416 & 0,000 & 0,874 & 0,76 & 0,99 \\
\hline Agência de viagem & 11,949 & 416 & 0,000 & 0,825 & 0,69 & 0,96 \\
\hline $\begin{array}{l}\text { Propagandas de TV, } \\
\text { rádio, jornal e revista }\end{array}$ & 11,982 & 416 & 0,000 & 0,795 & 0,66 & 0,93 \\
\hline
\end{tabular}

Fonte - Dados da pesquisa

As mídias sociais como fontes de informação foram as variáveis que apresentaram menor diferença entre os dois estudos, o que levanta a hipótese da ação global dessas ferramentas, capazes de estimular sua utilização em todos os grupos, diluindo fatores culturais que determinam outros aspectos na vida do indivíduo.

\section{Hipóteses}

Os achados descritos e analisados nesta pesquisa estão, portanto, em acordo com a primeira hipótese de Fotis, Buhalis e Rossides (2012), de que as mídias sociais são predominantemente utilizadas antes da viagem para buscar informações, suposição criada a partir da literatura, mas que contradiz os dados encontrados pelos autores. Já a segunda hipótese, de que as informações sobre viagens em mídia social são mais confiáveis do que publicidade em meios de comunicação, agências de viagens e sites oficiais de turismo, foi confirmada no estudo anterior e parcialmente rejeitada nesta pesquisa, visto que a confiabilidade das mídias sociais para informações de viagem não é maior que a de sites oficiais de turismo, segundo os brasileiros entrevistados.

\section{CONCLUSÃO}

Esta pesquisa cumpriu seu objetivo de medir a influência das mídias sociais no planejamento de viagens dentro da amostra estudada, bem como de identificar o nível de confiança atribuído por ela às informações disponíveis nessas ferramentas. Foi possível contrapor os dados obtidos aos da pesquisa similar, a fim de reconhecer a relação de particularidades culturais com comportamentos diferenciados. A análise estatística deste estudo constatou ampla utilização de diferentes mídias sociais em todas as fases do planejamento de viagens, com predominância do pré-viagem, além do compartilhamento de informações e fotos no retorno. A confiabilidade das informações disponíveis em mídias sociais mostrou-se positiva e seu poder de influência no planejamento foi reconhecido pela maior parte dos entrevistados.

A ambição deste estudo foi levantar pontos de discussão e incentivo a novas pesquisas no contexto nacional, de modo a embasar tomadas de decisão referentes à atividade turística, seja pelo gestor de políticas públicas do destino, seja pelos agentes de viagem e demais grupos interessados no produto turístico. 
Apesar da busca pelo desenvolvimento de um estudo estruturado, com base estatística, a pesquisa apresenta limitações para a generalização dos resultados à população brasileira, uma vez que os questionários foram respondidos por voluntários, constituindo uma amostra não aleatória, com grande concentração na cidade de Belo Horizonte. Entretanto, os dados levantados podem ser úteis para prosseguimento da discussão sobre a relação entre turismo e mídias sociais, estimulando a realização de novos estudos e aprofundamento dessa temática.

Sugere-se, ainda, a partir dos achados descritos, maior investigação não apenas acadêmica, mas também de cunho prático, de modo a reconhecer a demanda do público dos sites oficiais de turismo e, assim, embasar investimentos assertivos nessa ferramenta potencial, considerada confiável. Faz-se imprescindível a escuta das contribuições dos turistas nas diferentes mídias sociais, com o intuito de direcionar ações estratégicas que estabeleçam e reforcem uma boa relação entre os vários agentes envolvidos na atividade turística e, complementarmente, incentivar e promover o uso das mídias sociais na organização e realização de viagens.

\section{REFERÊNCIAS}

BRASIL. Presidência da República. Secretaria de Comunicação Social. (2014). Pesquisa Brasileira de Mídia 2015: hábitos de consumo de mídia pela população brasileira. Brasília, DF: Secom.

CASALÓ, L. V., Flavián, C., \& Guinalíu, M. (2011). Understanding the intention to follow the advice obtained in an online travel community. Computers in Human Behavior, 27(2), 622-633. doi: 10.1016/j.chb.2010.04.013.

COX, C., Burgess, S., Sellitto, C., \& Buultjens, J. (2009). The role of user-generated content in tourists' travel planning behavior. Journal of Hospitality Marketing \& Management, 18(8), 743-764. doi: 10.1080/19368620903235753.

FOTIS, J., Buhalis, D., \& Rossides, N. (2012). Social media use and impact during the holiday travel planning process. In: M. Fuchs, F. Ricci, \& L. Cantoni (Eds.). Information and communication technologies in tourism (pp. 13-24). Vienna, AT: Springer.

KAPLAN, A. M., \& Haenlein, M. (2010). Users of the world, unite! The challenges and opportunities of Social Media. Business Horizons, 53(1), 59-68. doi: 10.1016/j. bushor.2009.09.003.

MACHADO, D. F. C. (2015). Fotografias de viagens nas redes sociais: um estudo sobre os efeitos da visualização de fotografias na imagem do destino e na intenção futura de visita (Tese de doutorado). Programa de Pós-Graduação em Administração, Universidade Federal do Rio Grande do Sul, Porto Alegre. Recuperado de http://bit.ly/2uRthSF.

PARRA-LÓPEZ, E., Bulchand-Gidumal, J., Gutiérrez-Taño, D., \& Díaz-Armas, R. (2011). Intentions to use social media in organizing and taking vacation trips. Computers in Human Behavior, 27(2), 640-654. doi: 10.1016/j.chb.2010.05.022.

WORLD Tourism Organization. (2008). International Recommendations for Tourism Statistics. United Nation Publication. United Nation. Recuperado de https://unstats.un.org/ unsd/tradeserv/tourism/manual.html.

XIANG, Z., \& Gretzel, U. (2010). Role of social media in online travel information search. Tourism Management, 31(2), 179-188. doi: 10.1016/j.tourman.2009.02.016. 